\title{
Contribution of engineering geology for the construction of a new museum gallery over an archaeological site at Lorvão Monastery, Portugal
}

\author{
Mário Quinta-Ferreira ${ }^{1^{*}}$ \\ Paulo M. Tiago ${ }^{2}$ \\ João Henriques ${ }^{3}$ \\ Santiago Alija ${ }^{4}$ \\ 1* Centro de Geociências, Dep. Earth Sciences, University of Coimbra, Rua Sílvio Lima, \\ 3030-790 Coimbra, Portugal.mqf@dct.uc.pt, Phone: +351912563901 \\ 2 Instituto Superior de Engenharia de Coimbra, Rua Pedro Nunes, 3030-199 Coimbra, \\ Portugal.pmaranha@isec.pt \\ 3 Instituto Pedro Nunes, Rua Pedro Nunes, 3030-199 Coimbra, Portugal. \\ jpquintela@ipn.pt \\ ${ }^{4}$ Centro de Geociências, International University of la Rioja. Grande Via Rey Juan \\ Carlos I, 41 26002, Logroño (La Rioja) Spain. santiago.alija@unir.net
}

\begin{abstract}
The rehabilitation of the Lorvão Monastery in Penacova, Portugal, included the construction of a new steel structure to house a museum gallery. The implementation of an archaeological excavation prior to construction revealed a mesh of ancient masonry walls, dating from the $16^{\text {th }}$ to the $18^{\text {th }}$ centuries, which needed to be preserved and made available for exhibition. To help understand the characteristics of this foundation ground, an engineering geology study was required, strongly conditioned by the presence of heritage, reduced space and difficult accessibility caused by the extensive temporary support used to ensure stability of the walls. The engineering geology study consisted of a detailed surface mapping, complemented by nondestructive in situ tests, the soil stiffness gauge (SSG) and the surface moisture-density gauge (SMDG) and by the use of the Bieniawski rock mass rating (RMR) geomechanical classification. Three geotechnical zones were defined. The non-invasive engineering geology study performed, proved suitable to provide the geotechnical information necessary to redesign and construct the steel structure over a challenging archaeological site, preserving the heritage.
\end{abstract}

\section{Keywords:}

Lorvão Monastery / archaeology / engineering geology study / SSG / SMDG / geotechnical zoning / engineering works / foundations

\section{Research aims}

The research aimed to improve the interaction between engineering geology, archaeology and civil engineering in the construction of an engineering structure over an archaeological site of significant heritage value. Using current site investigation techniques and tests was not feasible due to difficulties accessing the exploration equipment and to the high risk of destruction of the heritage. The alternative approach used was based on a detailed engineering geology mapping of the archaeology-excavated surfaces, complemented by nondestructive measurements with portable equipment (SSG and SMDG), and by the use of the Bieniawski RMR geomechanics classification. The 
engineering geology approach used, proved to be effective in obtaining the information needed for the appropriate design and construction of the foundations of the steel structure, assuring the preservation of the heritage.

\section{Introduction}

Seeking new utilizations for the Lorvão Monastery in Penacova, Portugal, the construction of a museum gallery was planned on the west and south courtyard of the cloister.

The archaeological excavations required by the project owner, Instituto de Gestão do Património Arquitéctonico e Arqueológico (IGESPAR), before construction, revealed buried ancient walls dating from the $16^{\text {th }}$ to the $18^{\text {th }}$ centuries; considered an invaluable heritage. The walls thus had to be preserved and made available for exhibition.

\section{History highlights}

The Lorvão Monastery (Fig. 1) is located 7 km southwest of Penacova and $19 \mathrm{~km}$ east of Coimbra in Portugal [1]. The monastery would most certainly have been founded in the $9^{\text {th }}$ century after the Christian reconquest of Coimbra in AD 878 [2, 3, 4]. The building ceased to be a monastery in 1887 . The classification of National Monument was attributed in 1910 [4].

The monastery has undergone several renovations over the centuries (Fig. 1b). At the end of the $16^{\text {th }}$ century, a new renaissance cloister was built, surrounded by 13 chapels. The baroque balcony was added in the middle of the $17^{\text {th }}$ century, followed by several other improvements to the building. The construction of a new building for the novices was undertaken at the beginning of the $18^{\text {th }}$ century. The present church was rebuilt between 1748 and $1761[3,4]$. After important rebuilding in the $20^{\text {th }}$ century, the monastery was predominantly used as a psychiatric hospital until 2007. The new museum gallery was intended to be both a purpose-built exhibition space for the vast collection of valuable artistic items related to monastery life and its occupants, and as a way to provide funds to reduce running and maintenance costs.

\section{Work development}

In 2006 a preliminary study, without any site investigation, was carried out in preparation of the construction of a contemporary steel structure, mostly stone cladded, in delicate contrast to the existing constructions, to be built over an area of the garden. The archaeological excavation undertaken at the beginning of construction revealed a mesh of masonry walls belonging to ancient construction phases of the monastery (Fig. 2a). To redefine the structural foundations in this complex framework an engineering geology study of the ground was requested. As the archaeological works necessitated deep excavations within the fragile ancient walls, intensive temporary support was used which left a significantly reduced available space. The use of geophysical exploration was not possible due to the depth of the excavation, and the reduced space between walls and the large number of metallic props and wood braces supporting the walls and to the buried chapels adjacent to the cloister. Use of mechanical exploration was also rejected due to the lack of space and the difficulty of positioning a drilling unit within the fragile ancient walls; such a procedure would have risked serious damage to the archaeological structures. 
The engineering geology study developed was thus based on a detailed surface engineering geological mapping, complemented by nondestructive in situ tests, using light, small and easy to handle equipment (SSG and the SMDG) and by using the RMR geomechanical classification.

\section{Characteristics of the SSG}

The Soil Stiffness Gauge (SSG) causes very small vibrations on 25 different frequencies between 100 and $196 \mathrm{~Hz}$, that are transmitted to the ground by the ring shaped foot (Fig. $2 c$ ), measuring the resulting deformation and the average value is displayed $[5,6]$. The deformation of the soil $(\delta)$ is proportional to the Young's modulus (E), the shear modulus $(\mathrm{G})$, the Poisson's ratio $(\mathrm{v})$ and to the outside radius (R) of the ring foot. Dividing the force $(\mathrm{P})$ by the deflection $(\delta)$, the stiffness $(\mathrm{K})$ is obtained. The stiffness for a ring load in an elastic half-space is given by [7]: $\mathrm{K}=(\mathrm{P} / \delta)=(3.54 \mathrm{GR}) /(1-v)$. The stiffness modulus of the ground is computed using the relation $\mathrm{Eg}=\mathrm{K}(1-\mathrm{v} 2) / 1.77 \mathrm{R}$ [5]. The test procedure used was based on the ASTM Standard D6758 (2008) [8].

\section{Characteristics of the SMDG}

The surface moisture-density gauge (SMDG) has radioactive sources and radiation detectors enabling measurement of the in-place density and moisture of the ground by direct transmission, backscatter, or backscatter/air-gap ratio methods [9]. The rod of the SMDG containing cesium-137 emits gamma radiation (photons) which is then measured by the detector at the base of the gauge. The photons collide with a large number of electrons, reducing the amount reaching the detector in proportion to the density of the material. The nuclear gauge also uses a $40 \mathrm{mCi}$ source of americium-241: beryllium generating 70000 neutrons per second [10]. The neutrons are used to indirectly measure the hydrogen content of the material because when colliding with the hydrogen atoms they undergo thermalization (the fast neutrons, otherwise known as epithermal neutrons, emitted by the source are decelerated to speeds at which additional collisions with hydrogen or other molecules cannot slow them further). The thermalized neutrons are counted by He-3 detectors, which assess their number proportional to the hydrogen content of the material.

\section{The RMR geomechanics classification}

In the geomechanics classification of Bieniawski the RMR value is obtained by summing the tabulated ratings of the following six parameters: the uniaxial compressive strength of rock material, the rock quality designation (RQD), the spacing of discontinuities, the condition of discontinuities the groundwater conditions and the orientation of discontinuities [11]. The sum of the individual ratings allows categorization into one of the five classes. Despite the initial proposal being intended for tunnels the RMR is also used for slopes [12] and foundations [13, 14]. The RMR classification facilitates estimation of the geomechanical properties of the ground (cohesion, friction angle and allowable bearing capacity).

\section{Site investigation}

The geological materials exposed after the archaeological excavation, on both the floor and walls, were mapped in order to determine their distribution and characteristics. The lithology, texture, color, weathering grade and structure of the ground materials were assessed through direct observation. In order to quantify the geotechnical properties of 
the ground materials a complementary nondestructive test campaign using the SSG and SMDG was performed across 23 test locations (Fig. 3). While the SSG gathers data on stiffness, which is then converted into stiffness modulus [5, 6] important for the evaluation of the interaction between the ground and the structure, the SMDG determines the dry density [9], necessary to evaluate the weathering grade of the shale and the compactness of the soils.

\section{Geotechnical zoning}

The field data was analyzed and interpreted to evaluate the features considered relevant for the implementation of the foundations of the steel structure. The qualitative data obtained during the engineering geology mapping was complemented by the RMR geomechanical classification and by the quantitative results provided by the SSG and SMDG. The data enabled definition of three geotechnical zones (Fig. 3), assumed to be homogeneous in terms of their material properties and behavior. Geotechnical zone 1 (GZ1) present the best properties, includes the weathered shale, much fractured, showing a mainly brown or grayish color. Geotechnical zone 2 (GZ2) corresponds to the decomposed shale, usually brownish or yellowish in color, but still showing a schistose structure. The range of values measured in both zones showed that the properties of GZ1 and GZ2 (Table 1) were more similar than anticipated. Despite that, it was considered justifiable to maintain the two zones as separate, because their identification on site was clear, and GZ2 presented the worst properties because its shale was more prone to degrading. Geotechnical zone 3 (GZ3) includes all the soils (topsoil and earth fill). It is the worst zone due to its heterogeneity, low strength and high deformability.

To evaluate the variability of the test results obtained in situ, the Coefficient of Variation (COV) was used. For the stiffness modulus, the range computed for the COV is from $39 \%$ to $52 \%$, being similar to the range reported by [15] for the coefficient of consolidation (33\% to $68 \%$ ) or even to the COV range for compressibility (18\% to $73 \%$ ) reported by [16]. For the dry unit weight the COV presented in Table 1 ranging from $7.6 \%$ to $11.1 \%$ and the bulk unit weight from $6.8 \%$ to $11.8 \%$, being close to the ranges reported by [15] for the unit weight (3\% to 7\%) and for the buoyant unit weight (0 to 10\%). It must be highlighted that all the COV values presented refer to natural or uncontrolled materials and thus, are prone to showing significant dispersion due to natural variability and heterogeneity.

The results of the RMR for both the weathered shale $(\mathrm{RMR}=27)$ and the decomposed shale (RMR $=23$ ) were classified as class IV (RMR from 21 to 40), corresponding to a weak rock mass quality. For class IV the cohesion of the rock mass ranged between 100 and $200 \mathrm{kPa}$, and the angle of internal friction went from $15^{\circ}$ to $25^{\circ}$ [11]. The fourth quartile of the range was attributed to GZ2 due to its poor characteristics, while the third quartile was attributed to GZ1 (Table 1). The allowable bearing pressure was obtained using the RMR rating in the table and the graphic relation presented by [13]. The values obtained were crosschecked with the Portuguese code of practice [17] and the personal experience of the designer. Due to its weak properties, GZ3 was not recommended as a foundation.

\section{Construction of the steel structure}

The emplacement of the footings for the new structure on the free space between the archaeological wall remains and the buried chapels (Fig. 4) was carefully chosen. Rising from the footings, steel columns helped to reduce the clear floor span. The footings 
consisted of a set of small bored reinforced concrete blocks, with sufficient load carrying capacity. A small pit was excavated around $0.5 \mathrm{~m}$ by $0.5 \mathrm{~m}$ in plan and with a depth as small as possible (in most cases $0.8 \mathrm{~m}$ ), and the footings were cast in place using a geotextile to line the excavated pit.

The whole structure and finishing turned out to be a light construction with relatively small loads at foundation level. Also due to its characteristics, the structure is flexible enough not to be overly sensitive to small differential settlements that may occur in the near future [18].

\section{Conclusions}

The approach used consisted of an engineering geology study where the qualitative data obtained by the detailed surface mapping was complemented by the quantification provided both by nondestructive in situ testing (SSG and SMDG) and by the Bieniawski's RMR. Three geotechnical zones were considered: weathered shale (GZ1), decomposed shale (GZ2) and soil/earth fill (GZ3). They helped to understand the distribution of the geological materials and their properties, allowing a suitable design and construction of the foundations of the steel structure over the archaeological site. The construction of the foundations was carried out minimizing ground interference, in order to preserve the archaeological site. The constructed steel structure performed excellently, fulfilling the engineering goals and preserving the valuable heritage. The methodology used, despite being simple and cost effective, was proven suitable for the geotechnical characterization of the archaeological site.

\section{Acknowledgments}

This work was funded by the Portuguese Government through FCT - Fundação para a Ciência e a Tecnologia under the projects PEst-OE/CTE/UI0073/2011 and PEstOE/CTE/UI0073/2014 of the Centro de Geociências. The facilities for obtaining the data are acknowledged to IGESPAR and to the company Veiga Lopes, Lda.

\section{References}

[1] Google Maps, Google, 2014.

[2] T.L. Antunes, Lorvão: um mosteiro e um lugar. Análise e reconstituição. MSc Thesis, University of Coimbra, Portugal, 2013. (in Portuguese)

[3] N.C. Borges, Arte Monástica em Lorvão: sombras e realidade: I das origens a 1737, Ph.D. thesis, University of Coimbra, 1992. (in Portuguese)

[4] IGESPAR, Mosteiro de Lorvão - detalhe (accessed in 2012-02-06), http://www.igespar.pt/pt/patrimonio/pesquisa/geral/patrimonioimovel/detail/7069 4/

[5] Humboldt, GeoGaugeTM user guide, Model H-4140, Soil stiffness/modulus gauge (Version 4.0), Norridge, IL: Humboldt Mfg. Co, USA, 2007.

[6] M. Quinta-Ferreira, Ground stiffness evaluation using the soil stiffness gauge (SSG), in: G. Lollino, D. Giordan, K. Thuro, C. Carranza-Torres, F. Wu, P. Marinos, C. Delgado (Eds.), Engineering Geology for Society and Territory. Springer 6, 259262, 2015. doi: 10.1007/978-3-319-09060-3.

[7] H.G. Poulos, E.H. Davis, Elastic solutions for soil and rock mechanics, John Whiley and Sons, New York, 1974.

[8] ASTM Standard D6758, Standard test method for measuring stiffness and apparent modulus of soil and soil aggregate in-place by an electro-mechanical method, 
ASTM International, West Conshohocken, PA 2003, USA, 2008, doi: 10.1520/D6758-08, www.astm.org.

[9] ASTM Standard D6938, Standard Test Method for In-Place Density and Water Content of Soil and Soil-Aggregate by Nuclear Methods (Shallow Depth). ASTM International, West Conshohocken, PA 2003, USA, 2010, doi: 10.1520/D6938-10, www.astm.org.

[10] Troxler, Manual of operation and instruction, Model 3440, Surface Moisture-density Gauge, Troxler Electronics Laboratories, Inc, 3008 Cornwallis Rd, Research Triangle Park, NC 27709, USA, 2009.

[11] Z.T. Bieniawski, Engineering Rock Mass Classification, New York, John Wiley, 1989.

[12] M.R. Romana, A geomechanical classification for slopes: slope mass rating, in: J. A. Hudson (Editor-in-Chief), Comprehensive rock engineering. Principles, practice \& projects, v.3, Pergamon Press, 1993.

[13] B. Singh, R.K. Goel, Rock mass classification. A practical approach in civil engineering. Elsevier, 1999.

[14] M. Romana, DMR, a new geomechanics classification for use in dams foundations, adapted from RMR, $4^{\text {th }}$ International Symposium on Roller Compacted Concrete (RCC) Dams, Madrid, 2003.

[15] J.M. Duncan, Factors of safety and reliability in geotechnical engineering. Journal of Geotechnical and Geoenvironmental Engineering, 126 (2000) 307-316, doi: http://dx.doi.org/10.1061/(ASCE)1090-0241(2000)126:4(307).

[16] B.G. Look, Handbook of geotechnical investigation and design tables, Taylor \& Francis Group, London, 2007.

[17] LNEC E 217, Current shallow foundations - recommendations. Laboratório Nacional de Engenharia Civil, Lisbon, 1968.

[18] ECA Projectos, Reabilitação e reutilização do claustro do Mosteiro do Lorvão, fundações e projeto estrutural do novo edifício, IGESPAR, Coimbra, 2009. (in Portuguese) 

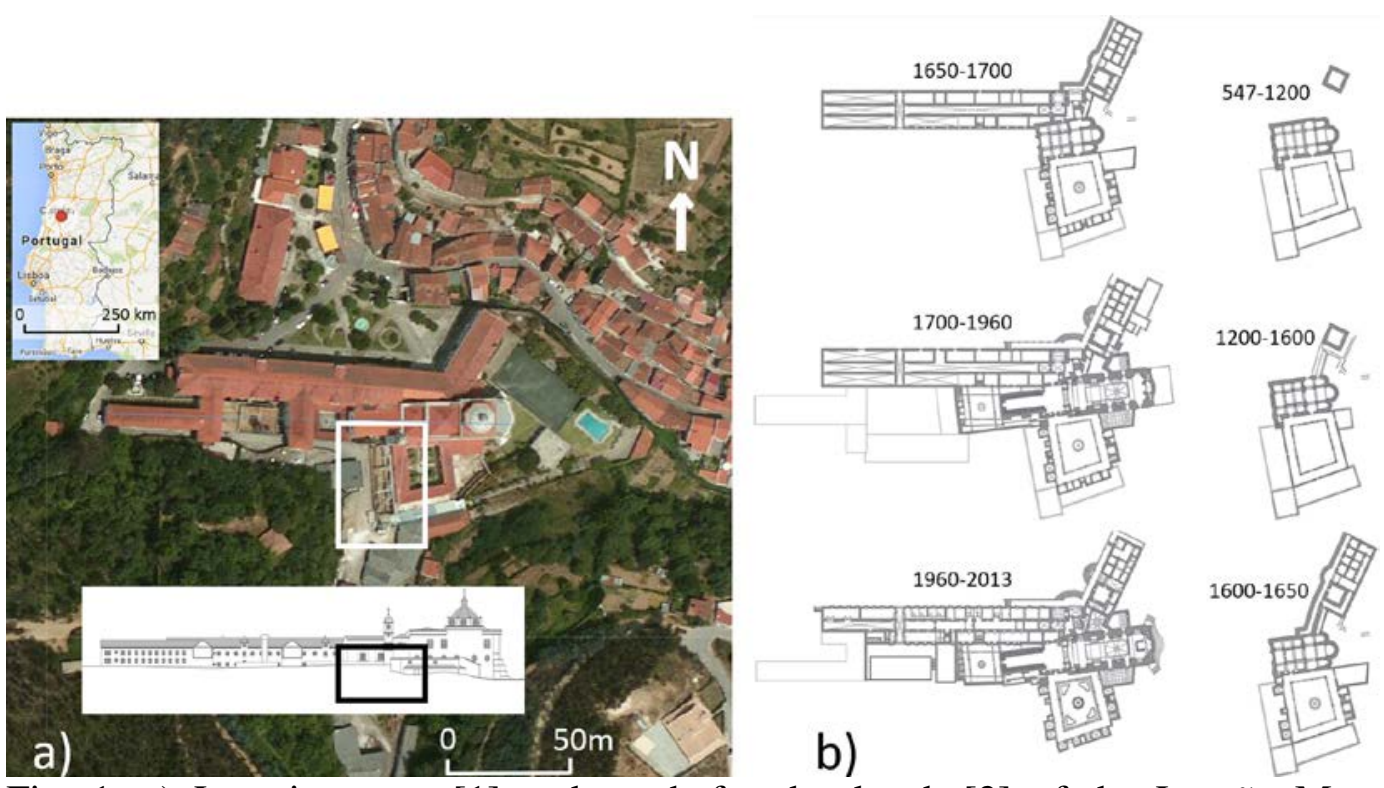

Fig. 1. a) Location map [1] and south façade sketch [2] of the Lorvão Monastery, Penacova, Portugal, from a satellite view. The studied area is delimited by a rectangle; $b$ ) Evolution of the ground plan of the Lorvão Monastery between AD 547 and AD 2013 (modified from [2]).
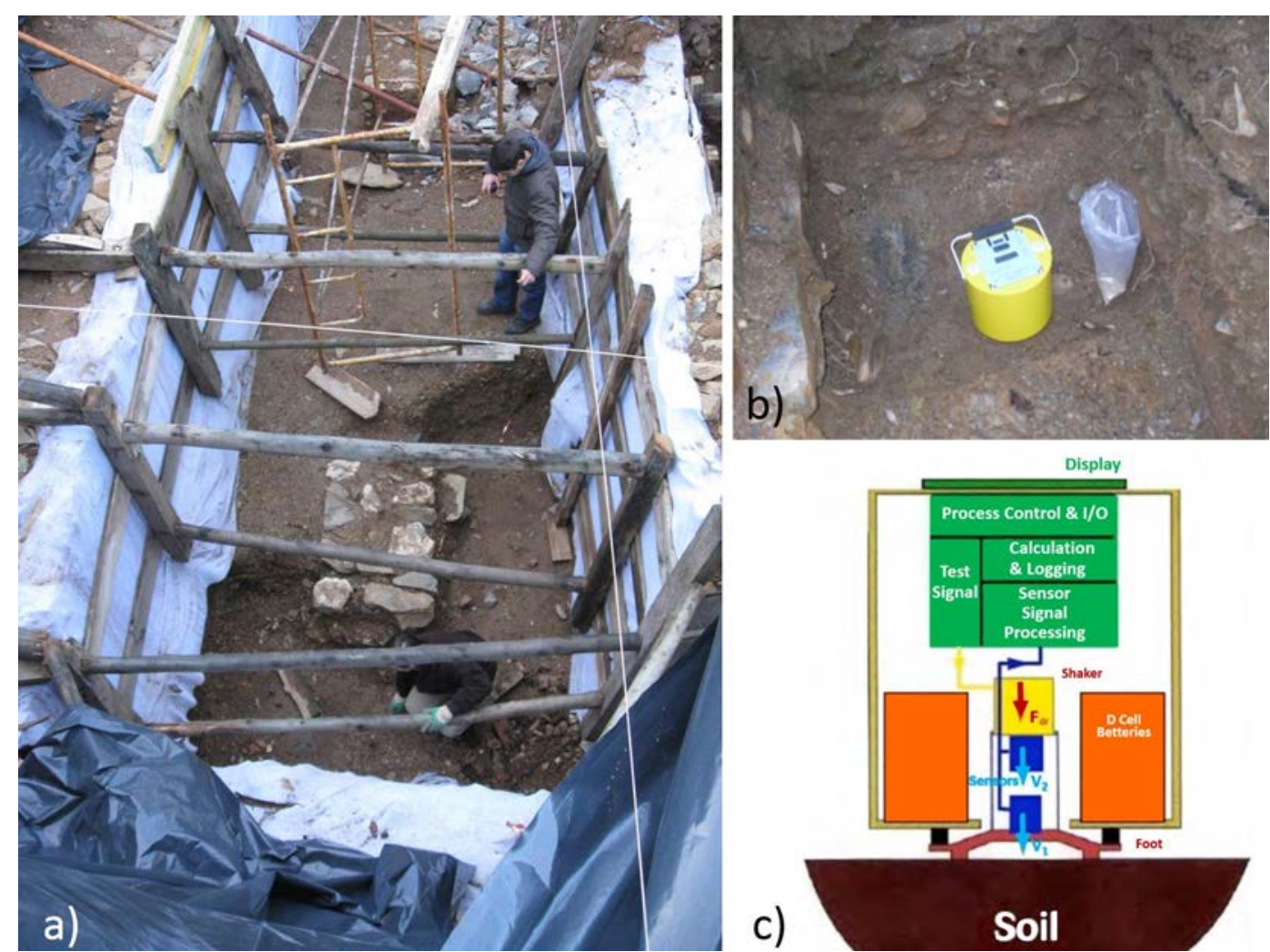

isplay

Fig. 2. Site details after the archaeological excavation: a) view of the extensive support of the ancient walls protected by geosynthetic and plastics; b) test with the SSG; c) schematic of the GeoGauge [5]. 


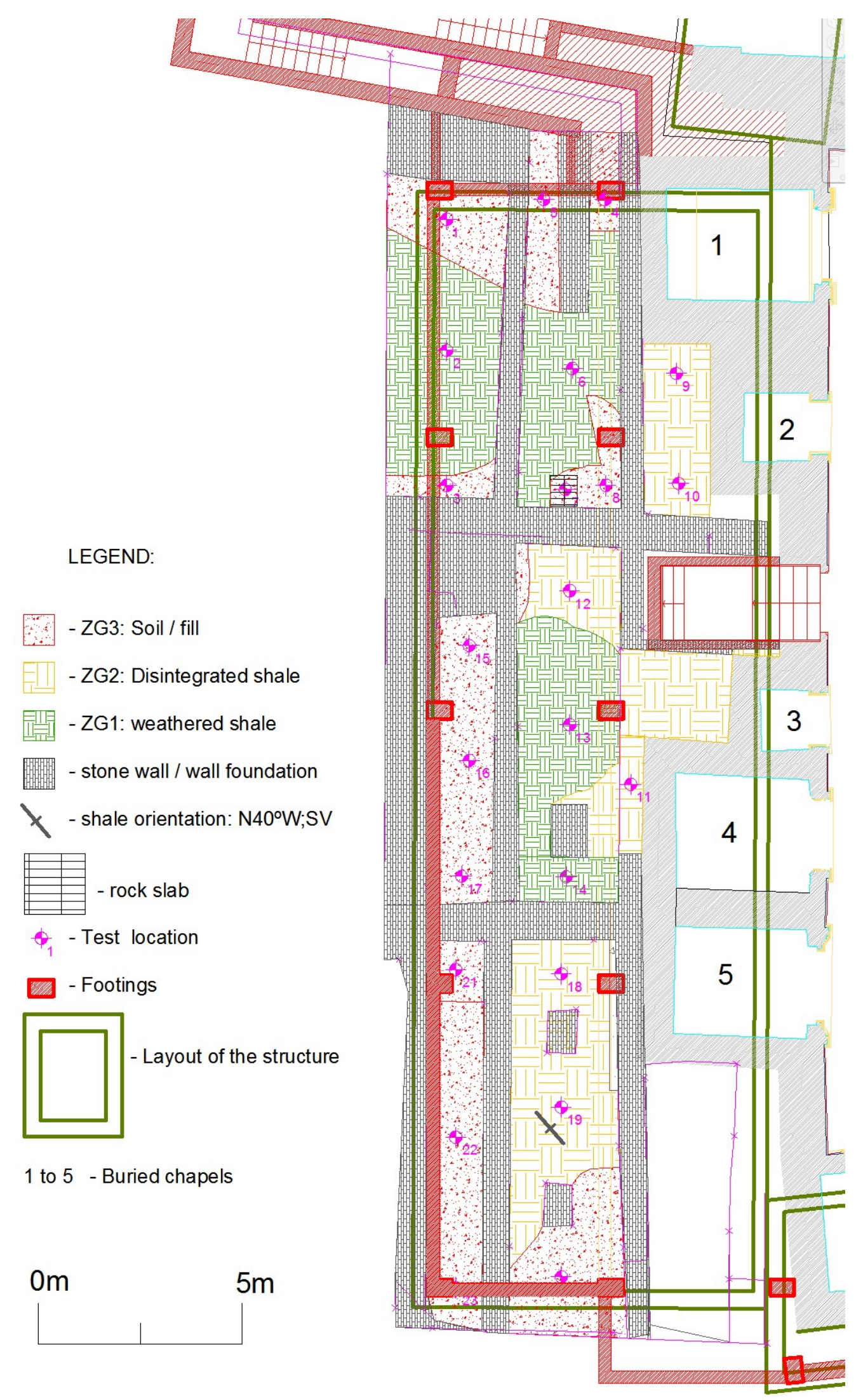

Fig. 3. Layout of the geotechnical zones. 

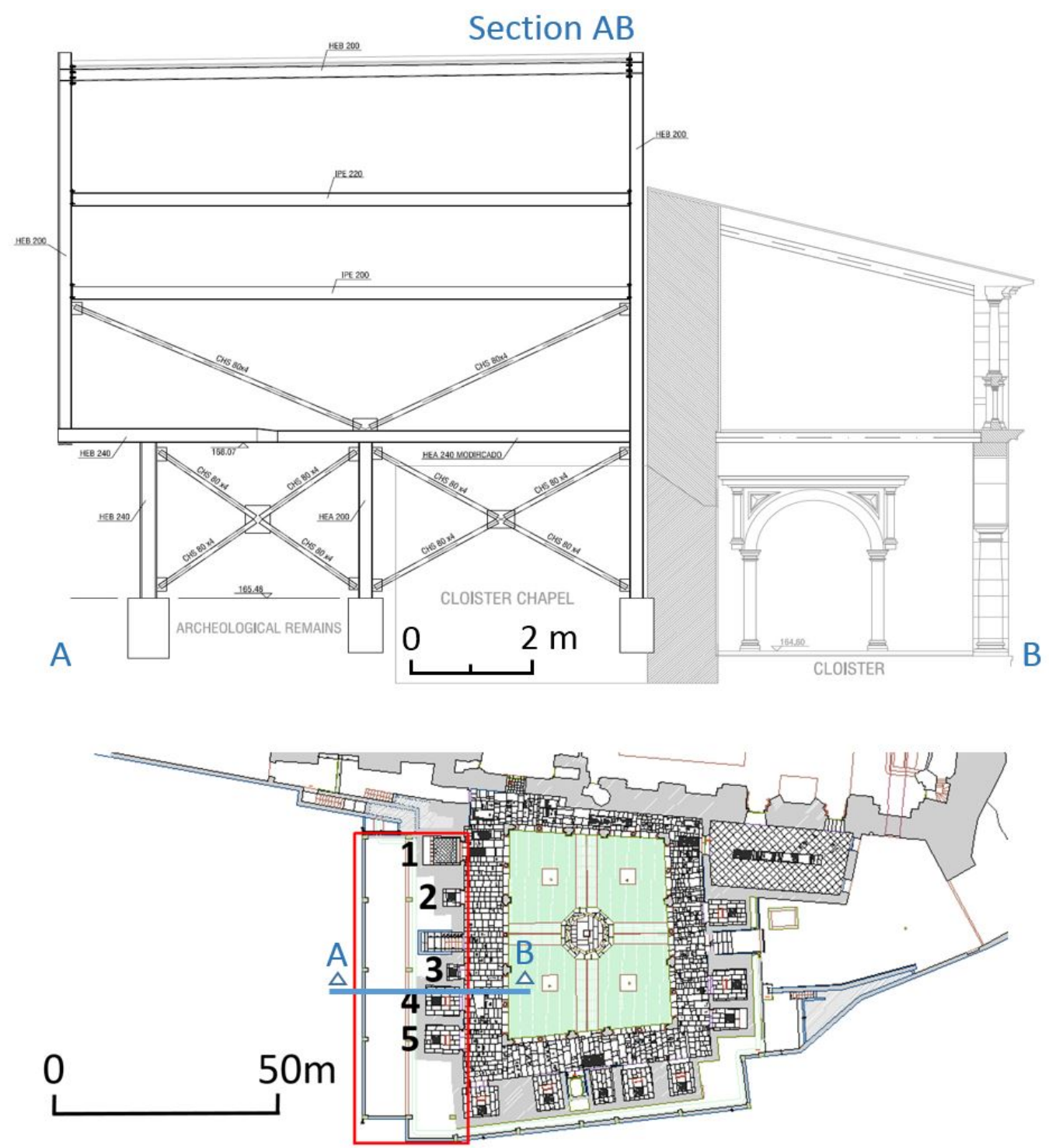

Fig. 4. Cross section showing a braced frame unit, its relative position and footings [18]. The buried chapels are numbered from 1 to 5 . 